\title{
GESTÃO DE REDES DE MOVIMENTOS SOCIAIS: UM BREVE ESTUDO SOBRE A REDE AGROECOLÓGICA ECOVIDA
}

Juliana de Jesus Grigoli*

\section{INTRODUÇÃo}

Um dos mais calorosos debates sobre os movimentos sociais contemporâneos articula reflexões teóricas acerca dos conceitos de sociedade civil organizada, identidade e cidadania com a análise da diversidade de práticas sociais voltadas à emancipação humana e a experiência da democracia participativa.

O ponto de partida dos debates é o entendimento histórico da trajetória dos movimentos sociais. A análise histórica de Eric Hobsbawn sobre as grandes revoluções europeias do século XIX ${ }^{1}$, os ensaios analíticos de Raymond Willians em O Campo e a Cidade, as abordagens de Marx e de autores marxistas sobre o movimento dos trabalhadores, os estudos feministas entre outros são fontes históricas importantes para compreender o que são os movimentos sociais na atualidade e como as relações sociais se organizam tendo em vista a definição de estratégias e ações políticas voltadas à inclusão social, a valorização e o reconhecimento das múltiplas identidades.

Tendo em vista estas contribuições Boaventura de Sousa Santos em Pela Mão de Alice, argumenta que a diversificação dos movimentos sociais ocorridos a partir da década de 1960 é, em parte, decorrente de uma crise da cidadania social vivida nos Estados Unidos e em alguns países da Europa. A crise do Estado Providência e o fortalecimento do movimento estudantil são os principais fatores destacados por Santos (1996) durante sua análise. A crise do Estado Providência aparece associada às transformações tanto no campo econômico, com a crise do regime de acumulação do capital pautado no fordismo e no taylorismo e a adoção gradual de um novo regime de acumulação do capital neoliberal, quanto no campo políticocultural, marcado pelo declínio do movimento dos trabalhadores e pelo fortalecimento de movimentos sociais mais específicos.

O movimento estudantil, na visão de Santos (1996), representou o grande articulador desta crise político-cultural do fordismo. Os principais pontos de confrontação foram: oposição

\footnotetext{
* Aluna de doutorado do Programa de Pós Graduação em Sociologia Política - CFH/UFSC.

${ }^{1}$ Análise sobre as grandes revoluções do século XIX disponíveis na obra Era das Revoluções.
} 
ao produtivismo e ao consumismo, às opressões cotidianas, e a declaração da hegemonia operária nas lutas pela emancipação social.

Esse estado de crise evidenciou algo que Santos (1996), tratou como a revolta da subjetividade contra a cidadania, isto é, da subjetividade pessoal e solidária contra a cidadania atomizada e paralisada. Essa revolta da subjetividade contra a cidadania somada ao fortalecimento dos novos movimentos sociais - NMS contribuiu para o aquecimento dos debates no campo político, em especial sobre a relação entre o conceito de democracia e as experiências participativas da sociedade civil organizada.

Para Santos (1996) a democracia participativa só faz sentido se resultar de um processo social que envolva a reconstrução do conceito de cidadania alicerçada na valorização do sentido de comunidade e no surgimento de novas teorias comprometidas com o fortalecimento das racionalidades locais.

No campo da práxis, a reconstrução do conceito de cidadania a partir das racionalidades locais e as estratégias pró-emancipação social impulsionaram os debates sobre identidade e diferença no interior dos novos movimentos sociais. Estudos desenvolvidos por Dussel (2005), Scherer-Warren (2006), Munanga (2003), demonstram que a afirmação da identidade ou mesmo a reconstrução do conceito de cidadania são conseqüências de uma série de processos sociais direcionados a tomada de consciência do ser coletivo. No caso latino-americano, Dussel (2005) e Scherer-Warren (2008) argumentam que a tomada de consciência passa pelo entendimento das relações de poder estabelecidas nos plano global e local.

Em relação às estratégias de emancipação social, Scherer-Warren (2006) identifica novos formatos de organização da sociedade civil. Nesse estudo a autora destaca as redes de movimentos sociais como uma das inovações sociais contemporâneas que permite novas configurações das relações políticas. Tendo em vista essas considerações, o conceito de movimento social é entendido como:

[...] uma ação grupal para a transformação (a práxis), voltada para a realização dos mesmos objetivos (o projeto), sob a orientação mais ou menos consciente de princípios valorativos comuns (a ideologia) e sob uma organização diretiva mais ou menos definida (a organização e sua direção). (SCHERER-WARREN, 1989, p.20) 
Sob esse ponto de vista, pode-se compreender o conceito de rede de movimento social como uma ampliação mais sofisticada do conceito de movimento social. Nesse sentido Scherer-Warren esclarece que:

A ideia da rede de movimento social é, portanto, um conceito de referência que busca apreender o porvir ou o rumo das ações de movimento, transcendendo as experiências empíricas, concretas, datadas, localizadas dos sujeitos/atores coletivos. (SCHERER-WARREN, 2006, p.113)

Os estudos de Scherer-Warren (2006) sobre a atuação em rede dos movimentos sociais demonstram o quanto as inovações nas formas organizativas das relações sociais e políticas possibilita o alcance de resultados consistentes no campo dos direitos.

Pesquisas recentes nas áreas da sociologia rural, agricultura familiar, segurança alimentar e movimentos sociais dedicam-se a analisar como os movimentos sociais ligados a questão agrária se organizam para construírem suas ações e estratégias políticas voltadas as suas necessidades. Nesse contexto, pode-se destacar a pesquisa desenvolvida por Santos \& Mayer (2007) e os trabalhos de Brandenburg (2011) que tratam do movimento agroecológico e da importância da participação dos atores sociais para a construção de novas perspectivas de produção e geração de renda.

Assim, a proposta deste artigo é compreender a estrutura e a gestão das redes dos movimentos sociais como uma estratégia política que reúne sujeitos e atores sociais em torno de debates mais profundos sobre os conceitos de identidade, cidadania, emancipação social e democracia participativa, é o principal objetivo do presente estudo. Para tanto, toma-se como objeto de análise as experiências organizativas da Rede Agroecológica EcoVida.

A primeira parte do trabalho está centrada no debate conceitual procura unificar os conceito de movimentos sociais e redes sociais. Em seguida, apresenta-se uma descrição dos métodos utilizados na realização da pesquisa. A terceira parte do estudo trata-se de um histórico acompanhado de uma análise sobre as formas organizativas da Rede EcoVida. E, por fim, a quarta e última parte do trabalho consiste num debate sobre as novas formas de participação política tendo como ponto de partida o modelo de gestão adotado pela EcoVida. 


\section{METODOLOGIA DE PESQUISA}

A pesquisa foi dividida em três etapas. A primeira delas consiste na realização de pesquisa bibliográfica sobre os conceitos de movimentos sociais e redes de movimentos sociais e fazer, paralelamente, um breve mapeamento da produção teórica sobre o tema onde tivemos os trabalhos de Santos (1996) e de Scherer-Warren (2006) como principais fontes. Além disso, efetuou-se leituras de materiais impressos pela Rede EcoVida e de materiais disponíveis na página oficial da Rede. A segunda parte consiste em um breve trabalho de campo, com o acompanhamento das atividades desenvolvidas pela EcoVida durante o Encontro da Rede em julho de 2008, e com a realização de três entrevistas fechadas com articuladores regionais e membros da Rede EcoVida. A terceira e última etapa da pesquisa consiste na análise sobre o tema proposto cruzando os conceitos abordados com as práticas observadas em campo e as entrevistas coletadas.

\section{MOVIMENTOS SOCIAIS E AS NOVAS FORMAS DE ORGANIZAÇÃO COLETIVA}

O campo de atuação dos movimentos sociais sofreu, nos últimos 30 anos, uma série de transformações decorrentes da diversificação e da complexificação de suas formas de atuação política, social e cultural. De acordo com Santos (1996), a década de 80 foi marcada pela emergência dos novos sujeitos e movimentos sociais e pela "afirmação de suas identidades específicas, o reconhecimento público de seus valores, o respeito pelas diferenças culturais e a conquistas por novos direitos" (SCHERER-WARREN, 2000, p.41). Sobre esse mesmo assunto Ligia Lüchmann, no artigo Identidades e Diferenças no Movimento Comunitário de Florianópolis, destaca:

[...] com a democratização do Estado, a globalização e a crescente multiplicidade do tecido social, a oposição binária (movimentos sociais $X$ Estado) implode, seja pela multiplicidade de projetos e interesses no campo do associativismo civil, seja pela diversificação (e abertura) da esfera estatal. (LÜCHMANN, 1989, p.20)

Assim, a concepção de identidade - e de diferença - sofre alterações na medida em que passa a "ser vista como contingente, isto é, como produto de uma intersecção de diferentes 
componentes, de discursos, políticos e culturais e de histórias particulares" (WOODWARD apud LÜCHMANN, 1989, p.20).

O resultado decorrente da ampliação dessa complexidade se manifesta com a diversificação das formas de organização da sociedade civil com o objetivo de mobilizar recursos, fomentar debates, organizar e dar visibilidade as ações no terreno da práxis. Para llse Scherer-Warren (2006), sociedade civil significa:

[...] a representação de vários níveis de como os interesses e os valores da cidadania se organizam em cada sociedade para encaminhamento de suas ações em prol de políticas sociais e públicas, protestos sociais, manifestação simbólicas e pressões políticas. (SCHERER-WARREN, 2006, p.113)

Direcionada por esse entendimento de sociedade civil, a autora define rede de movimento social como o resultado desse processo articulatório dos diversos níveis de atuação da sociedade civil organizada, cujos níveis de atuação dividem-se em quatro tipificações. No nível primário encontra-se o associativismo local composto por associações e fundações sem fins lucrativos e de interesse público, civis, os movimentos comunitários e os sujeitos sociais que atuam em diversas frentes sociais. Num nível secundário identifica-se as formas de articulação inter-organizacionais, "dentre as quais se destacam os fóruns da sociedade civil, as associações nacionais de ONGs e as redes de redes, [....] representando organizações de movimentos do associativismo local" (SCHERER-WARREN, 2006, p.111). No nível terciário estão às redes que organizam as mobilizações na esfera pública, que sintetizam as manifestações e as necessidades das organizações dois primeiros níveis. E no quarto e último nível aparecem os apoios financeiros, em especial as agências de fomento nacionais e internacionais. À luz destas concepções, busca-se tecer algumas análises em relação às formas de organização e atuação da Rede EcoVida.

\section{BREVE ESTUDO SOBRE O MODELO SE GESTÃO DA REDE AGROECOLÓGICA ECOVIDA}

\subsection{HISTÓRICO}

A Rede EcoVida iniciou suas atividades em 1998, num processo de reação ao impasse político em torno de um projeto de normatização e certificação dos produtos agroecológicos encaminhados pelo Estado de Santa Catarina. Impulsionados pelo impasse e pela falta de 
diálogo com as instituições públicas catarinenses, os agricultores agroecológicos da região Sul do Brasil se solidarizaram e formaram a Rede EcoVida.

Num primeiro momento, a motivação para o surgimento da Rede foi a necessidade de superar os impasses políticos relacionados à falta de incentivo financeiro para o pequeno produtor rural do Sul do Brasil. Após esse período e vencido alguns obstáculos, a Rede EcoVida se fortaleceu com a ampliação dos debates relacionados as necessidades do trabalhador do campo, o aumento da participação com surgimento de novos atores e sujeitos, o refinamento da metodologia de trabalho com a adoção de estratégias de trabalho transversal partindo de debates horizontalizados e de atividades de fortalecimento da identidade do agricultor agroecológico, e, por fim, o alinhamento das propostas encaminhadas ao Ministério da Agricultura Familiar de acordo com as estratégias de gestão e de mobilização social.

Atualmente a Rede congrega 300 grupos de agricultores, 26 núcleos e 08 cooperativas, coordena 21 núcleos regionais e está presente em 170 municípios dos Estados do Paraná, Santa Catarina e Rio Grande do Sul. Suas ações políticas abrangem a formação e capacitação de seus membros, articulação política para fortalecimento da agroecologia, intercâmbios e trocas de experiências, realização de parcerias com entidades e movimentos que compartilham do mesmo princípio, sistematização de experiências e elaborações teóricas afins, informação, comunicação, divulgação da proposta da Rede, comercialização solidária, realização de feiras e encontros, apoio às organizações de base e por fim avaliação da conformidade participativa e a certificação participativa.

\subsection{NÍVEIS DE ARTICULAÇÃO DA REDE}

Os espaços e as dinâmicas organizativas da Rede EcoVida são compostos de vários níveis. No primeiro nível, de atuação local, encontram-se as organizações e os movimentos locais, formados pelas famílias agricultoras e consumidoras, por associações sem fins lucrativos, por cooperativas de produção, entidades de assessoria, pequenos comerciantes e pessoas membros da Rede. No segundo nível, de atuação regional, estão os Núcleos Regionais, definidos como os espaços que reúnem os membros da Rede numa determinada região e os membros da coordenação geral.

No nível três estão a Plenária de Núcleos e a Plenária dos Estados. A Plenária de Núcleos da Rede se responsabiliza pelo aprofundamento dos temas regionais. E a Plenária de 
Núcleos do Estado se responsabiliza por dar encaminhamentos as discussões e reivindicações da Plenária de Núcleos da Rede.

Por fim, no quarto nível está a Assembleia Geral que ocorre no Encontro Ampliado da Rede. De acordo com um dos articuladores da rede, "o encontro ampliado é o grande momento coletivo da Rede porque promove discussões políticas, trocas de experiências, oficinas temáticas, feiras dos sabores e dos saberes, e realiza-se a Assembleia Geral". Segundo os materiais impressos coletados durante o Encontro da Rede EcoVida em julho de 2008 em Garopaba - SC, a Assembleia Geral é um dos momentos mais marcantes, no qual ocorre a homologação para a criação de novos núcleos, eleições para a coordenação geral, e tomada de decisões de acordo com as necessidades e diretrizes definidas pelo grande grupo.

\subsection{MODELO DE GESTÃO DA ECOVIDA}

De acordo com as observações realizadas em campo o modelo de gestão da EcoVida visa a superação dos limites impostos pelas instituições e pelos estados nacionais. "É uma forma de resistência e enfrentamento, de propor e fazer, de buscar o fortalecimento político de uma concepção de organização social em oposição a outras redes e formas de organização do capital das empresas, do agronegócio" (CADERNO DE FORMAÇÃO 01-Rede EcoVida, 2007, p.36).

Balizada por essa concepção de rede social, a EcoVida adaptou e desenvolveu um modelo de gestão adequado as suas necessidades e aos contextos sociais e culturais específicos de cada Estado envolvido no processo. O modelo está fundamentado na horizontalidade das relações sociais entre seus membros e na habilidade de articular os diversos níveis envolvidos. Na opinião de uma das articuladoras da rede, "a horizontalidade permite o exercício da cidadania de acordo com uma visão de democracia mais participativa, onde os grupos estão reunidos para debater e tomar decisões de impacto global e local".

A descrição do modelo de gestão adotado pela Rede EcoVida aparece no regimento interno criado em 1998 aprovado por seus membros. Em linhas gerais, o documento está dividido em alguns tópicos, tais como: missão, objetivos, princípios, valores e explicação sobre a sua forma de organização. A análise desses tópicos revelou que há uma sintonia interessante entre a missão e a forma de organização adotada pela Rede. Assim, a missão define-se como "um espaço de articulação, interação e ação para potencializar o desenvolvimento da 
agroecologia, como parte da construção de um projeto de sociedade que contemple a realidade de cada povo" (CADERNO DE FORMAÇÃO 01-Rede EcoVida, 2007, p.14). De acordo com a Figura 1, a forma de organização da Rede acompanha a missão da organização já que a articulação regional destas iniciativas forma os Núcleos, que é o principal espaço organizacional e funcional da Rede.

Figura 1: Diagrama organizacional da Rede EcoVida

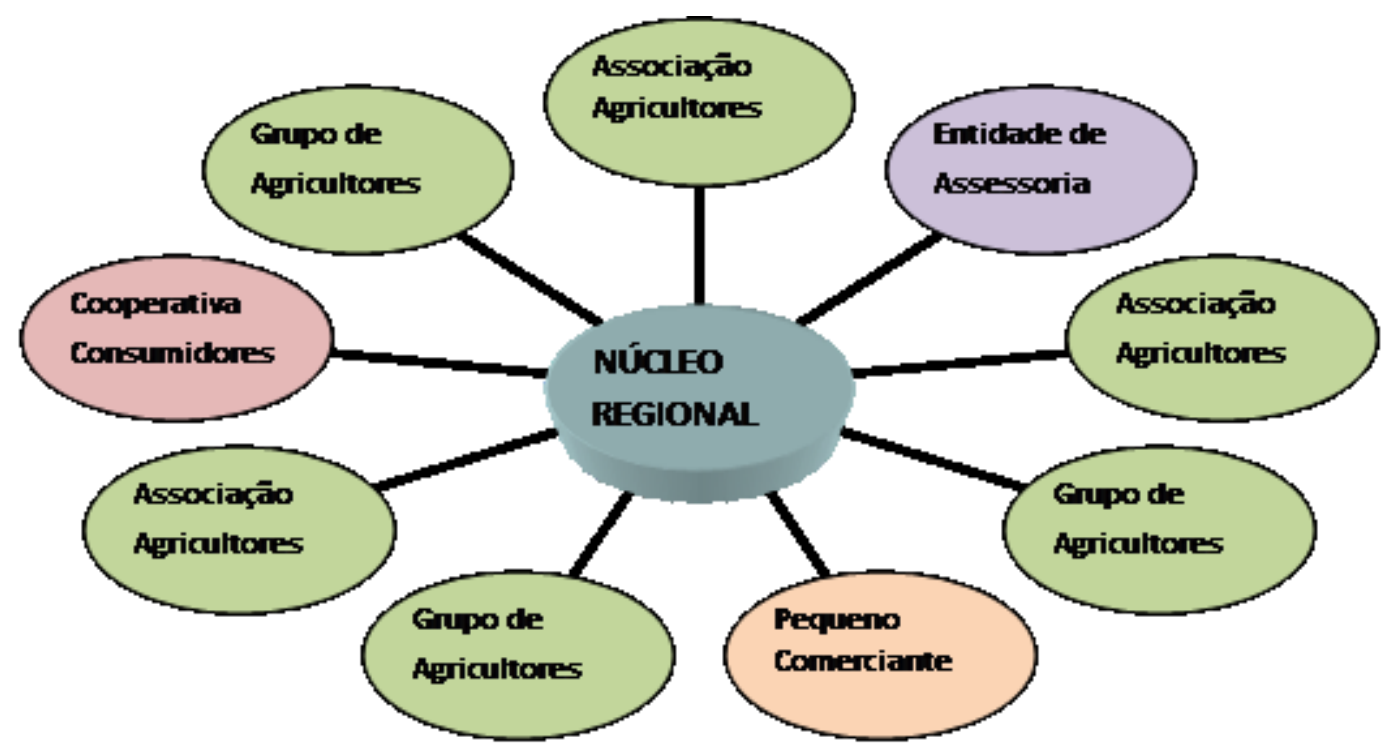

Fonte: Diagrama elaborado a partir das observações de campo

Numa dimensão mais ampla, a Rede se articula de uma maneira funcional sem perder seu caráter subjetivo e identitário. Com estratégias eficientes de comunicação e uma árvore de atuação bem definida, a Rede articula suas ações de forma horizontal, privilegiando o diálogo entre os grupos e núcleos envolvidos nos processos decisórios. A Figura 2 ajuda a compreender como a EcoVida estabelece suas relações políticas para o alcance de seus objetivos. 
Figura 2: Diagrama da organização dos grupos e núcleos que participam da Rede EcoVida

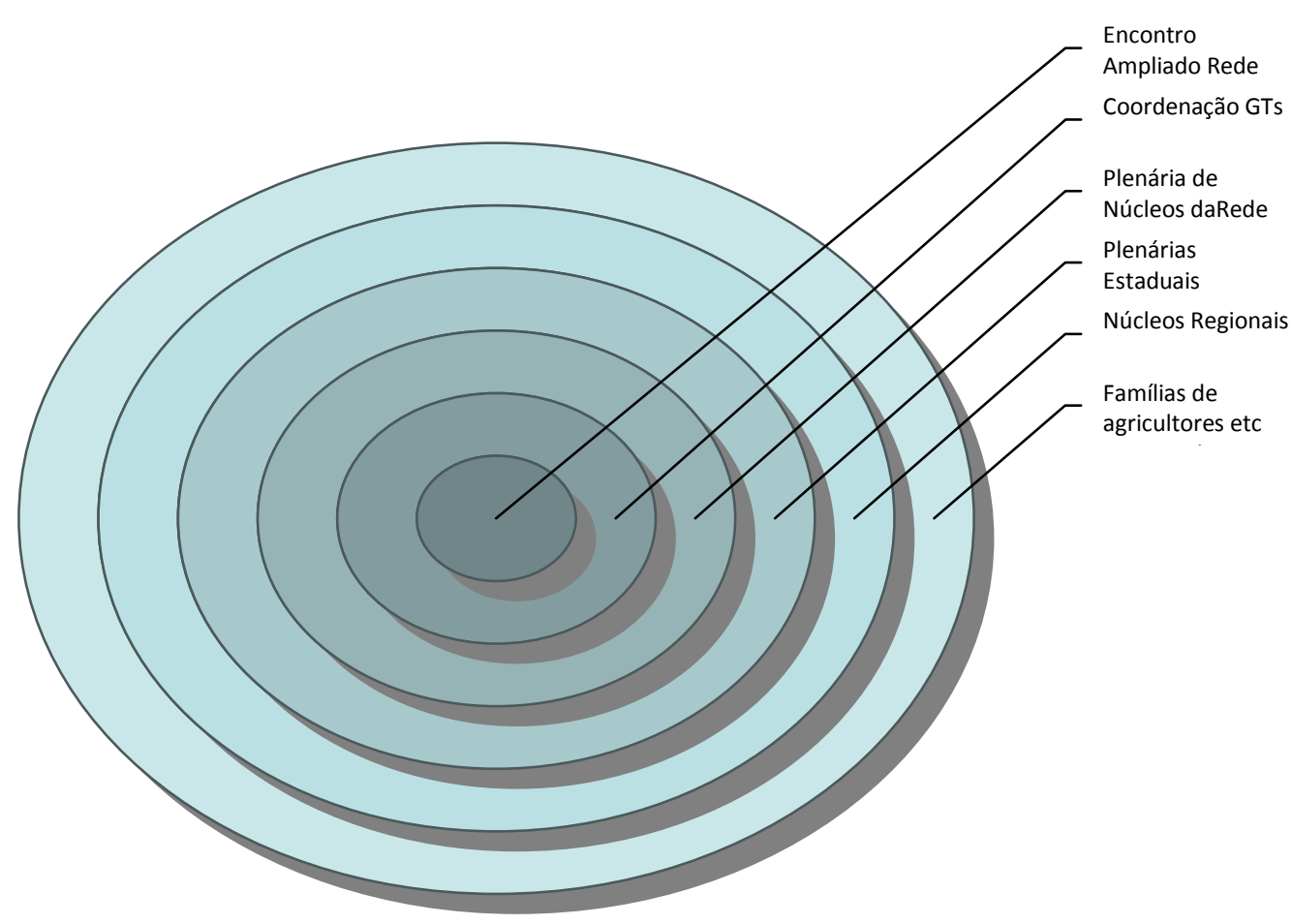

Fonte: Diagrama elaborado a partir das observações de campo

Orientados por essa forma de gestão, a EcoVida participa ativamente de outras redes de movimentos sociais. No plano nacional, participa das redes do Movimento Sem Terra - MST, Via Campesina e Movimento dos Pequenos Agricultores - MPA. No plano internacional, participa também de duas redes - Slow Food e Fundação Interamericana de Desenvolvimento. A gestão destas parcerias é administrada por membros da Rede EcoVida, eleitos democraticamente nas Plenárias de Núcleos ou as Estaduais com o compromisso de representar a organização nos encontros virtuais (no caso de redes pela internet) e nos encontros presenciais. De acordo com o depoimento de uma das articuladoras da rede, "[...] a formação da Rede foi essencial na vida das famílias e dos agricultores do Sul do Brasil, 
principalmente porque o modelo de gestão adotado foi um resultado de uma série de decisões tomadas no plano coletivo".

As Plenárias dos Núcleos e as reuniões entre os representantes estaduais da Rede ocorrem de forma transversal. Os debates e as ações configuradas nestas ocasiões abrangem os seguintes segmentos: a) gênero e geração com destaque às mulheres agricultoras e a juventude do campo; b) campo da agricultura familiar e camponesa, cuja discussão abrange a re-significação do campo e do novo papel da agricultura familiar e camponesa no desenvolvimento social e econômico; c) acompanhamento dos resultados alcançados e a identificação dos desafios da Rede.

Com esse compromisso, a Rede mantém, desde 2002, grupos de trabalhos permanentes que discutem e propõem soluções dentro dessas perspectivas. $\mathrm{O}$ depoimento de uma das participantes da EcoVida confirma essa proposição ao dizer "[...] eu gosto dos encontros dos grupos de trabalho, eu participo no grupo que discute gênero, sempre fico sabendo de novidades e posso dar minha opinião sem medo".

Os assuntos e deliberações dos grupos de trabalhos permanentes são encaminhados aos Núcleos das Redes e desses para os Núcleos dos Estados. Em geral todos os temas abordados que geram encaminhamentos são contemplados nas atividades desenvolvidas durante os encontros e finalizados na Assembleia Geral proposta pela Rede. Na opinião de um dos membros da Rede exposto no Relatório Parcial do Projeto de Tecelagem Manual ${ }^{2}$ (2008, p.04): "a forma como a Rede faz o seu trabalho é o segredo para as conquistas. Eu me sinto bem por participar dessa iniciativa que luta pelos direitos das mulheres agricultoras".

Este depoimento evidencia a potencialidade transformadora de uma gestão pautada no equilíbrio entre os diversos interesses em jogo somados a uma política interna que privilegia o empoderamento e o exercício da cidadania participativa. Nesse sentido, a análise dos resultados conquistados pela Rede revelou que há uma estreita correlação entre o fortalecimento da identidade do agricultor(a) agroecológico(a) no Sul do Brasil e a elevação na qualidade de vida dos mesmos.

\footnotetext{
${ }^{2}$ Relatório disponível na Associação CEPAGRO - uma das instituições que participam da Rede EcoVida.
} 


\section{REDES SOCIAIS E PARTICIPAÇÃO POLÍTICA}

A partir da análise do modelo de gestão da Rede EcoVida pode-se depreender que os movimentos sociais organizados em redes tem maiores condições de construir uma política emancipatória capaz de superar os limites da democracia representativa vigente - que limita a participação política ao voto, e das incongruências da democracia participativa. De acordo com Santos $(2007$, p.93) "[...] os estudos que temos sobre os pressupostos participativos, por exemplo, ainda em nível local, como em Porto Alegre, mostram claramente que todas as formas de democracia participativa têm também elementos de representação".

Ao negar o caráter representativo herdado da política formal, a Rede EcoVida estabelece novos parâmetros de relacionamento interpessoal, enfatizando a horizontalidade das relações sociais e políticas.

Embora haja uma forma organizativa distribuída em níveis, a experiência do trabalho de campo revelou que não há uma relação de poder hierárquica entre as instituições participantes. O acompanhamento das atividades desenvolvidas pela EcoVida demonstrou que as decisões definidas nas Assembleias Gerais fundamentam-se nos encaminhamentos realizados pelos grupos de trabalhos e pelas plenárias abertas.

Esse caráter de atuação permite um dinamismo que potencializa as tomadas de decisões a partir de uma interação transversal, criando um espaço de diálogo entre os sujeitos e os atores sociais. A interação transversal aparece como um elemento chave no processo decisório, possibilitando a definição de uma pauta mais ampla. Desse modo, a multidimensionalidade dos debates e das ações políticas engendradas pelos agentes da EcoVida, visam superar os limites de uma democracia representativa ao permitir a "passagem da defesa de um sujeito identitário único à defesa de um sujeito plural" (SCHERER-WARREN, 2006, p.116). De acordo com o posicionamento oficial da Rede EcoVida,

\footnotetext{
Além das dimensões ecológicas, as experiências populares de agroecologia incorpora as dimensões sociopolíticas e culturais produzidas pelos movimentos sociais. Hoje não é mais possível pensar num amplo projeto agroecológico, ou num movimento agroecológico, sem reforçar pautas de outros grandes movimentos como bandeira de luta: MST, MMC, MAB, MPA, FETRAF, CONTAG, MIQCB, MMM, CPT, FEAB, entre outros. Isso traz a luta contra as desigualdades e a exclusão social para a pauta da EcoVida (CADERNO DE FORMAÇÃO 01, 2007, p.32).
} 
Por fim, cabe destacar que as experiências políticas das redes e dos movimentos sociais contemporâneos contribuem para o avanço das reflexões e do debate sobre o projeto político democrático vigente e lança, assim, reflexões para a construção de uma cidadania mais participativa e dinâmica, com abertura dos espaços políticos para as diversas vozes que exprimem as necessidades e os anseios da sociedade civil organizada.

\section{CONSIDERAÇÕES FINAIS}

As reflexões teóricas acerca dos conceitos de sociedade civil organizada, identidade e cidadania, somadas a análise da diversidade das práticas dos movimentos sociais contemporâneos articulados em redes revelaram aspectos que contribuem significativamente para o avanço do debate voltado à emancipação humana.

Esse debate abrange a análise dos movimentos e das redes sociais tanto em dimensões mais amplas (globais) quanto em dimensões mais restritas (locais). Na dimensão global os movimentos estão empreendendo ações que colocam em xeque alguns aspectos essenciais dos sistemas democrático e econômico vigentes. Na América Latina, por exemplo, os movimentos sociais de ampla atuação estão conectados a debates que entendem a exclusão e a discriminação social como um resultado histórico de subalternidade às culturas europeias e norte-americanas. Esse entendimento estimula os movimentos a buscarem soluções de alto impacto, explorando, assim, suas potencialidades de negociação e comunicação junto aos diversos atores sociais, incluindo os Estados e o mercado.

Nas dimensões locais, destaca-se o fortalecimento das identidades dos sujeitos unitários e dos sujeitos plurais, da implementação de uma diversidade de ações, dos engajamentos, das metodologias e das estratégias sintonizadas as necessidades cotidianas dos grupos sociais.

Enfim, estudar os movimentos sociais e suas estratégias de mobilização social é entrar em contato um novo modelo de organização social e uma nova forma de fazer político. O que leva ao questionamento: será que estamos vivendo um momento de transição da democracia representativa para uma democracia participativa, que valorize a participação, alicerçado num movimento sustentado por amplas alianças populares entre os diversos setores e movimentos sociais? 


\section{REFERÊNCIAS}

BRANDENBURG, Alfio. Os novos atores da construção do ambiente rural no Brasil: o movimento ecológico na agricultura. In: Revista Estudos Sociedade Agricultura, ano 19, v.1, 2011.

DUSSEL, Enrique. Europa, modernidade e eurocentrismo. In: LANDER, Edgard (org.) A colonialidade do saber: eurocentrismo e ciências sociais. Perspectivas latino-americanas. Buenos Aires - Argentina, 2005, pp.55-70.

HELD, David. Modelos de Democracia. Belo Horizonte, MG: Paidéia, 1987.

HOBSBAWN, Eric. A Era das Revoluções. Rio de Janeiro: Editora Paz e Terra, 1991.

MUNANGA, Kabengele. Diversidade, etnicidade, identidade e cidadania. Ação Educativa, ANPED. Palestra proferida no 10 Seminário de Formação Teórico Metodológica, SP. 2003. Disponível em: <http://www.acaoeducativa.org/kabe.PDF>. Acesso em 28/jul/2006.

LÜCHMANN, Lígia H.H. et. all. Identidades e Diferenças no Movimento Comunitário de Florianópolis, In: SCHERER-WARREN, I \& CHAVES, I.M. (orgs.), Associativismo Civil em Santa Catarina: trajetórias e tendências. Florianópolis: Insular, 2004.

OLIVEIRA, Heloísa Maria José. A Democracia em suas versões elitista e participativa e o modelo da autonomia democrática. In: Revista Katálysis, Florianópolis: UFSC, v.6, 2003.

PATEMAN, C. Participação e teoria democrática. Rio de Janeiro: Paz e Terra, 1992.

REDE ECOVIDA. Caderno de Formação 01. Paraná: Lapa, 2007.

RELATÓRIO PARCIAL DO PROJETO DE TECELAGEM MANUAL CEPAGRO, 2008.

SANTOS, Boaventura de Sousa. Pela Mão de Alice. Porto: Afrontamento, 1996. 
Tradução Mouzar Benedito, SP: Boitempo, 2007.

\section{Renovar a Teoria Crítica e Reinventar a Emancipação Social.}

SANTOS, Luis Carlos Rebelatto \& MAYER, Paulo Henrique. A experiência da Rede EcoVida de Agroecologia no Sul do Brasil. In: Revista Brasileira de Agroecologia, v.2, n.2, 2007. Disponível em: www.aba-agroecologia.org.br.

SCHERER-WARREN, Ilse. Das Mobilizações as redes de movimentos sociais. Revista Sociedade e Estado, UNB, V.21, n.1, 2006, p. 109-130.

SCHERER-WARREN, Ilse. Redes de movimentos sociais na América Latina: caminhos para uma política emancipatória? In: Cadernos CRH (online), 2008 vol. 21, n.54.

Movimentos sociais e pós-colonialismo na América Latina. Palestra na Mesa Redonda "Ações coletivas, movimentos e redes sociais na contemporaneidade". XIV Congresso Brasileiro de Sociologia, RJ, 2009.

WILLIAMS, Raymond. Campo e Cidade. São Paulo: Cia das Letras, 1989. 


\title{
RESUMO
}

Compreender a estrutura e a gestão das redes dos movimentos sociais como uma estratégia política que reúne sujeitos e atores sociais em torno de debates mais profundos sobre os conceitos de identidade, cidadania, emancipação social e democracia participativa, é o principal objetivo do presente estudo. Para tanto, tomaremos como objeto de análise as experiências organizativas da Rede Agroecológica EcoVida. A primeira parte do trabalho procura unificar os conceito de movimentos sociais e redes sociais. Em seguida, apresenta-se uma descrição dos métodos utilizados na realização da pesquisa. A terceira parte do estudo trata-se de um histórico acompanhado de uma análise sobre as formas organizativas da Rede EcoVida. E, por fim, a quarta e última parte do trabalho consiste num debate sobre as novas formas de participação política tendo como ponto de partida o modelo de gestão adotado pela EcoVida.

PALAVRAS-CHAVE: Movimentos sociais. Redes de movimentos sociais. Gestão social. Participação. Democracia.

\begin{abstract}
Understanding the structure and management of social movements networks as a political strategy that brings together individuals and social actors around deeper debates on the concepts of identity, citizenship, social empowerment and participatory democracy, is the main objective of this study. To do so, we will take as the object of this analysis the organizational experiences of Agroecology Network EcoVida. The first part of the paper seeks to to unify the concept of social movements and social networks. Then, presents a description of the methods used in the research. The third part of the study it is a historical background accompained by an analysis of the organizational Network EcoVida. And finally, the fourth and final part of the paper is a discussion of new forms of political participation taking as its starting point the management model adopted by EcoVida.
\end{abstract}

KEYWORDS: Social movements. Social movements networks. Social management. Participation. Democracy.

Recebido em: 29 set. 2012

Aceito para publicação em: 05 jul. 2013 